\title{
Atividade do extrato hidroetanólico das folhas de Raphanus Sativus em glândulas submandibulares de ratos com diabetes mellitus
}

Hydroetanolic extract activity of Raphanus Sativus leaves in submandibular glands of rats with diabetes mellitus

\author{
Actividad del extracto hidroetanólico de hojas de Raphanus Sativus en glándulas submandibulares \\ de ratas con diabetes mellitus
}

\section{Resumo}

Diabetes mellitus (DM) é uma doença identificada pelo elevado nível de glicose no sangue que é resultante de um defeito na secreção de insulina. Indivíduos com diabetes descontrolada apresentam alterações importantes na cavidade oral como a periodontite e hipossalivação, tornando mais predisposto à cáries, xerostomia, além de afetar a imunidade e aumentar a susceptibilidade à infecções. Neste estudo, avaliou-se a atividade do extrato hidroetanólico de Raphanus sativus (rabanete) na diminuição do estresse oxidativo em ratos wistar machos induzidos a diabetes através de Aloxano 
$(120 \mathrm{mg} / \mathrm{kg})$ e tratados em um período de 90 dias com o extrato hidroetanólico de Raphanus Sativus diariamente por gavagem, na concentração de $300 \mathrm{mg} / \mathrm{kg} / \mathrm{dia}$. O extrato testado apresentou resultados positivos, atuando na diminuição do estresse oxidativo, reduzindo a lipoperoxidação (MDA) e oxidação proteica nas glândulas submandibulares dos ratos com diabetes. O extrato hidroetanólico de Raphanus sativus possui propriedades antioxidantes capazes de reverter os danos causados pelo extressse oxidativo. Os resultados deste trabalho mostram que o extrato de Raphanus sativus pode ser tornar uma opção terapêutica para o controle dos danos da DM que envolvam a cavidade bucal.

Palavras-chave: Glândula submandibular; Raphanus; Estresse Oxidativo.

\begin{abstract}
Diabetes mellitus (DM) is a disease identified by the high level of glucose in the blood that results from a defect in insulin secretion. Individuals with uncontrolled diabetes have important changes in the oral cavity, such as periodontitis and hyposalivation, making them more predisposed to cavities, dry mouth, in addition to affecting immunity and increasing susceptibility to infections. In this study, the activity of the hydroethanolic extract of Raphanus sativus (radish) was evaluated in decreasing oxidative stress in male wistar rats with diabetes induced by using Alloxane (120 $\mathrm{mg} / \mathrm{kg}$ ) and treated over a 90-day period with Raphanus Sativus extract daily by gavage at a concentration of $300 \mathrm{mg}$ / kg / day. The tested extract showed positive results, since decreased oxidative stress was observed, as attested by evaluating lipoperoxidation (MDA) and protein oxidation in the submandibular glands of rats with diabetes. The hydroethanolic extract of Raphanus sativus has antioxidant effects, being able to reverse the damage caused by oxidative stress. The results of this work show that the extract of Raphanus sativus can become a therapeutic option for the control of oxidative damage from DM involving the oral cavity.
\end{abstract}

Keywords: Submandibular gland; Raphanus; Oxidative Stress.

\title{
Resumen
}

La diabetes mellitus (DM) es una enfermedad que se identifica por el alto nivel de glucosa en la sangre que resulta de un defecto en la secreción de insulina. Los individuos con diabetes no controlada tienen cambios importantes en la cavidad bucal, como periodontitis e hiposalivación, lo que los hace más predispuestos a las caries, sequedad de boca, además de afectar la inmunidad y aumentar la susceptibilidad a las infecciones. En este estudio, se evaluó la actividad del extracto hidroetanólico de Raphanus sativus (rábano) para reducir el estrés oxidativo en ratas wistar macho inducidas por diabetes usando Aloxano (120 mg / kg) y tratadas durante un período de 90 días con Extracto diario de Raphanus sativus por sonda a una concentración de $300 \mathrm{mg} / \mathrm{kg} /$ día. El extracto ensayado mostró resultados positivos, actuando en la reducción del estrés oxidativo, reduciendo la lipoperoxidación (MDA) y la oxidación de proteínas en las glándulas submandibulares de ratas con diabetes. El extracto hidroetanólico de Raphanus sativus tiene efectos antioxidantes capaces de revertir el daño causado por el estrés oxidativo. Los resultados de este trabajo muestran que el extracto de Raphanus sativus puede convertirse en una opción terapéutica para el tratamiento del daño de la DM que afecta a la cavidad oral.

Palabras clave: Glándula Submandibular; Raphanus; Estrés oxidativo.

\section{Introdução}

Diabetes Mellitus (DM) é uma doença caracterizada pelo aumento da glicose sanguínea devido os distúrbios do metabolismo. Manifesta-se por meio da ausência de produção de insulina pelo pâncreas, aumento da resistência periférica à insulina ou ambos os casos (Bartholomew et al., 1987; Escott-Stump, 2007). A classificação atual das diabetes se baseia na sua etiologia, sendo dividida em quatro classes: DM tipo1, DM tipo 2, outros tipos específicos e DM gestacional (American Diabetes Association, 2004). A DM já é considerada um problema de saúde pública, visto que houve um aumento de sua incidência nos últimos anos e consequente aumento da morbimortalidade associada, logos esses pacientes necessitam de acompanhamento médico e tratamento correto para que sejam evitadas comorbidades ou complicações causadas pelos danos oxidativos associadas à doença (Vasconcelos et al., 2007).

Os estudos acerca da avaliação do estresse oxidativo vêm adquirindo relevância significativa, pois os marcadores oxidativos contribuem com enfermidades crônicas degenerativas. Assim, são importantes ferramentas que possibilitam o planejamento de ações no controle e prevenção de doenças associadas (França et al., 2013). O estresse oxidativo acontece a partir de um desequilíbrio entre a geração de compostos oxidantes e os sistemas de defesa antioxidante (Barbosa et al., 2010). Esse desbalanço dos níveis de radicais livres e antioxidantes nas complicações da diabetes têm sido alvo de pesquisas na origem e desenvolvimento de complicações e manifestações sistêmicas, como complicações nas glândulas salivares, diminuição de resistência periodontal, aumento de infecções e entre outros acometimentos (Mauri-Obradors et al., 2019). 
Atrelado a isso, com a longevidade, a urbanização e com o aumento da obesidade e da inatividade física torna-se necessário a orientação ao paciente com DM aos hábitos de vida saudáveis, incluindo alternativas farmacológicas e terapêuticas para diminuir a glicemia e as complicações decorrentes da doença (Xu et al., 2017). O tratamento com fitoterápicos, produtos preparados à base de plantas, se trata de uma prática curativa natural desde os tempos mais remotos, e apesar de ter sido ao longo dos anos substituída por medicamentos sintetizados em laboratórios, ainda observa-se a ressurreição da medicina natural, baseada em plantas medicinais para a cura de diversas moléstias, o que tem incentivado pesquisas experimentais científicas para que se comprovem tais ações (Borba et al., 2006). Algumas plantas têm sido alvo de estudo científico a fim de comprovar os seus efeitos terapêuticos na DM sendo que apresentam potenciais propriedades hipoglicemiantes (Negri, 2005 \& Feijó et al., 2012).

O Raphanus sativus L, pertence à família Brassicaceae, popularmente conhecida como "rabanete" (Gancheva et al., 2016). O grupo desses vegetais crucíferos atuam como uma excelente fonte de antioxidantes naturais devido aos seus altos níveis de compostos fenólicos, incluindo, carotenóides, bem como ácido ascórbico e tocoferóis. Esses compostos possuem a capacidade de eliminar radicais livres ou evitar a oxidação de lipoproteínas de baixa densidade. Os efeitos preventivos e promotores de saúde dos compostos polifenólicos se tornaram assunto de interesse devido suas propriedades nutricionais e terapêuticas (Bergamaschi, 2010).

O objetivo desse trabalho foi avaliar a capacidade do extrato hidroetanólico das folhas de Raphanus sativus L. em diminuir o estresse oxidativo de glândulas salivares em ratos diabéticos.

\section{Metodologia}

\section{Tipo de pesquisa e animais}

Esta é uma pesquisa quantitativa (Pereira A.S. et al., 2018), onde foram utilizados 45 ratos da linhagem Wistar, machos, de 6 a 9 semanas, com peso corporal inicial próximo de 250g, fornecidos pelo Biotério da Universidade José do Rosário Vellano. Os animais foram mantidos no Laboratório de Experimentação Animal da Unifenas com controle de temperatura e controle de 12 horas no ciclo claro-escuro. Todos os animais foram mantidos em gaiolas com cama de maravalha, no total de 5 animais por gaiola. Todos os animais foram alimentados com ração peletizada e água filtrada, sendo submetidos a um período de adaptação de 10 dias.

\section{Indução da Diabetes Mellitus}

Para induzir a diabetes foi administrado, por via intraperitoneal, a droga diabetogênica. Aloxano na dose de $120 \mathrm{mg} / \mathrm{Kg}$ de peso corporal, dissolvido em salina $0,9 \%(\mathrm{pH} \mathrm{4,5)}$. Os animais que apresentaram glicemia acima de $200 \mathrm{mg} / \mathrm{dL}$ foram considerados diabéticos (Jaouhari et al., 2000).

\section{Preparação da solução do extrato hidroetanólico de Raphanus sativus}

As folhas de Raphanus sativus L. var. oleifera Metzg. foram coletadas no terreno localizado na avenida Afonso Pena, Jardim Boa Esperança, município de Alfenas, região Sul do Estado de Minas Gerais. Dados geográficos: 21²5'22.87" S; 4557'29.42” O; Altitude 842 metros. A identificação taxonômica da espécie R. sativus foi realizada, sendo depositada a exsicata 2279 no Herbário da Universidade Federal de Alfenas. As folhas de R. sativus passaram pelo processo de secagem em estufa de ar circulante (Solab ${ }^{\circledR}$ SL 102 ) a $45^{\circ} \mathrm{C}$ durante sete dias para a completa secagem até peso constante, em seguida foram trituradas em moinho de facas mecânico (CIENILAB CE-430) até obtenção do pó de granulometria moderadamente grossa, segundo os parâmetros definidos pela Organização Mundial de Saúde (1998).

O extrato hidroetanólico foi obtido utilizando método de extração de percolação exaustivo (Prista et al., 2014). O processo se iniciou com o umedecimento antecipado de 200 gramas da droga vegetal com álcool 70\% (v/v) durante 2 horas fora 
do percolador. Em seguida, o percolador foi preenchido com a droga vegetal umedecida e adicionar-se-á álcool 70\% (v/v), deixando-o em maceração por 7 dias. A vazão do percolado ficou em 1,0 ml/min/Kg de droga vegetal. O extrato hidroetanólico obtido foi levado ao aparelho de rotavapor sob pressão reduzida e temperatura controlada (aproximadamente $45^{\circ} \mathrm{C}$ ) para concentração do extrato líquido. Após a concentração, o extrato foi congelado em ultrafreezer UFR 30 (Liotop) a $-70^{\circ} \mathrm{C}$ e liofilizado pelo liofilizador L101 (Liotop). Obtido o extrato seco, o mesmo foi armazenado em frasco âmbar e mantido em dessecador.

\section{Desenho experimental}

Após injeção intraperitoneal com aloxana $(120 \mathrm{mg} / \mathrm{kg}$ ) ou com veículo (solução salina $0,9 \%$ ) os ratos foram mantidos com dieta padrão e foi realizado tratamento diário com extrato hidroetanólico das folhas de Raphanus sativus por 12 semanas. Os níveis de glicose e o peso dos animais foram avaliados uma semana após a indução da diabetes, para comprovar que os animais se tornaram diabéticos (a glicose sanguínea foi avaliada com um glicosímetro comercial usando sangue total da veia da cauda). Os ratos foram divididos em 3 grupos conforme mostrado na Tabela 1.

Tabela 1. Grupos experimentais.

\begin{tabular}{|l|l|l|l|}
\hline Grupo & $\mathbf{N}^{\mathbf{0}}$ de animais & Fármaco & Injeção (Indução de DM) \\
\hline Grupo 1: controle sem diabetes & 15 & - & Salina \\
\hline Grupo 2: controle diabéticos & 15 & - & Aloxana $(120 \mathrm{mg} / \mathrm{kg} / \mathrm{ml})$ \\
\hline $\begin{array}{l}\text { Grupo 3: diabéticos tratados com } \\
\text { extrato de Raphanus sativus }\end{array}$ & 15 & $\begin{array}{l}\text { Extrato hidroetanólico de } \\
\text { Raphanus sativus }(300 \mathrm{mg} / \mathrm{Kg})\end{array}$ & Aloxana $(120 \mathrm{mg} / \mathrm{kg} / \mathrm{ml})$ \\
\hline
\end{tabular}

Fonte: Autores.

\section{Sacrifício dos animais}

O método de indução de morte foi por aprofundamento anestésico para depressão bulbar, e, após isso, os animais foram armazenados em sacos plásticos com capacidade e resistência compatíveis com o peso. Posteriormente foram identificados e mantidos em freezer até a coleta por pessoal treinado e destinados a incineração.

\section{Preparo do homogeneizado de glândulas salivares}

O homogeneizado as glândulas submandibulares foram preparados como descrito na literatura (Jones et al., 1998). As glândulas foram retiradas e homogeneizadas a $4{ }^{\circ} \mathrm{C}$ em tampão fosfato (PBS, pH 7,2) $0,1 \mathrm{M}$ na proporção $5 \mathrm{~mL} / \mathrm{g}$ de órgão. $\mathrm{O}$ homogeneizado foi centrifugado a $3000 \mathrm{~g}$, por $10 \mathrm{~min} \mathrm{a} 4^{\circ} \mathrm{C}$, sendo utilizado o sobrenadante para a determinação da peroxidação lipídica e oxidação proteica (proteínas carboniladas).

\section{Avaliação da peroxidação lipídica}

A peroxidação lipídica foi determinada pela medida dos produtos de oxidação que reagem com o ácido tiobarbitúrico (TBARS). Alíquotas do plasma/homogeneizado $(150 \mu \mathrm{L})$ foram misturadas com $750 \mu \mathrm{L}$ de ácido fosfórico 1,22M, $1350 \mu \mathrm{L}$ de água deionizada e $750 \mu \mathrm{L}$ de TBA $(0,67 \%)$. Em seguida, as amostras foram aquecidas em banho de água fervente $\left(95^{\circ} \mathrm{C}\right)$, durante 1 hora. Após o resfriamento em banho de gelo $4^{\circ} \mathrm{C}$, em cubeta com capacidade de $3 \mathrm{~mL}$ foi adicionado $1800 \mu \mathrm{L}$ de metanol, 200 $\mu \mathrm{L}$ de $\mathrm{NaOH} 1 \mathrm{M}$ e $1000 \mu \mathrm{L}$ de amostra. A concentração de TBARS foi estimada a partir da curva padrão de dialdeído malônico (MDA; 1,1,3,3 tetraetoxipropano). Os resultados foram expressos em nmoles de MDA/g de proteína.

\section{Determinação da concentração proteica total}

As concentrações proteicas foram determinadas em todas as amostras de homogeneizados pelo método de Bradford 
(1976), utilizando-se albumina sérica bovina (BSA) como padrão da curva de calibração.

\section{Determinação de proteínas carboniladas (CPO)}

Para a determinação das proteínas carboniladas, $500 \mu \mathrm{L}$ das alíquotas em tampão PBS mais $500 \mu \mathrm{L}$ da solução 2,4dinitrofenilhidrazina $10 \mu \mathrm{M}$ foram incubadas por $1 \mathrm{~h}$, com gotejamento de $500 \mu \mathrm{L}$ da solução de ácido tricloroacético (TCA) $20 \%$, até a precipitação completa. $500 \mu \mathrm{L}$ da solução Etanol/Acetato de Etila foi acrescentado à mistura e esta foi centrifugada a $600 \mathrm{~g}$ por 10 minutos. Ao pellet resultante foi adicionado novamente $500 \mu \mathrm{L}$ da solução Etanol/Acetato de Etila e foi feita uma nova centrifugação $(600 \mathrm{~g}, 10$ minutos). Finalmente, o pellet foi dissolvido com $1000 \mu \mathrm{L}$ de Guanidina $6 \mathrm{M}$. A taxa da variação na absorbância foi medida espectrofotometricamente a $370 \mathrm{~nm}$.

\section{Análise dos resultados}

Os dados foram expressos como média (+/-) erro padrão da média. A análise de variância (ANOVA) seguida de teste Tukey foi utilizada para comparar as médias entre os 4 diferentes grupos. As diferenças foram consideradas significativas quando valor de $\mathrm{p} \leq 0,05$.

\section{Resultados e Discussão}

O efeito anti-hiperglicêmico do extrato hidroetanólico das folhas de $R$. sativus $L$. em ratos com DM tipo 1 foi demonstrado em um prévio estudo (Silva et al., 2019). Além disso, alguns estudos mostram que o efeito hipoglicêmico do rabanete está atrelado a melhora da sensibilidade ou exercendo atividade semelhante à insulina devido a um componente antioxidante responsável pelo efeito que estimula as células $\beta$ pancreáticas a liberarem mais insulina (Borba et al., 2006 \& Taniguchi et al., 2006). Outros compostos antioxidativos observados no extrato como compostos fenólicos, presença de flavonoide e vitamina E facilitam a entrada de glicose na célula-alvo (Banihani, 2017; Grochanke et al., 2016; Rocha Navarro et al., 2019; Taniguchi et al., 2006).

Por conta destes prévios achados, quanto as propriedades hipoglicemiantes atreladas aos antioxidantes, avaliamos um possível efeito deste extrato em prevenir o estresse oxidativo em ratos com DM, ligados ao efeito de diminuição da glicemia ou além deste efeito antihiperglicêmico, ou seja, atuando também diretamente no estresse oxidativo. Para avaliação do estresse oxidativo, foi avaliado o nível de malondialdeído (produto da oxidação lipídica) das glândulas submandibulares (Gráfico 1). Também foi avaliada a concentração de proteínas carboniladas (Gráfico 2) que corresponde ao produto da oxidação proteica. Sendo assim, foi avaliado o produto da lesão nessas biomoléculas pelo estresse oxidativo em ratos com DM tipo 1. O malonaldeido (MDA) é um biomarcador, produto secundário da peroxidação lipídica, derivado do rompimento de endociclização de ácidos gordos polinsaturados, tais como ácido linoléico, araquidônico e docosahexaenóico (França et al., 2013). O MDA é considerado, atualmente, um candidato potencial para ser escolhido como um biomarcador geral de lesão oxidativa em plasma (Grotto et al., 2008). 
Gráfico 1 - Níveis dos níveis de Malonaldeído (MDA).

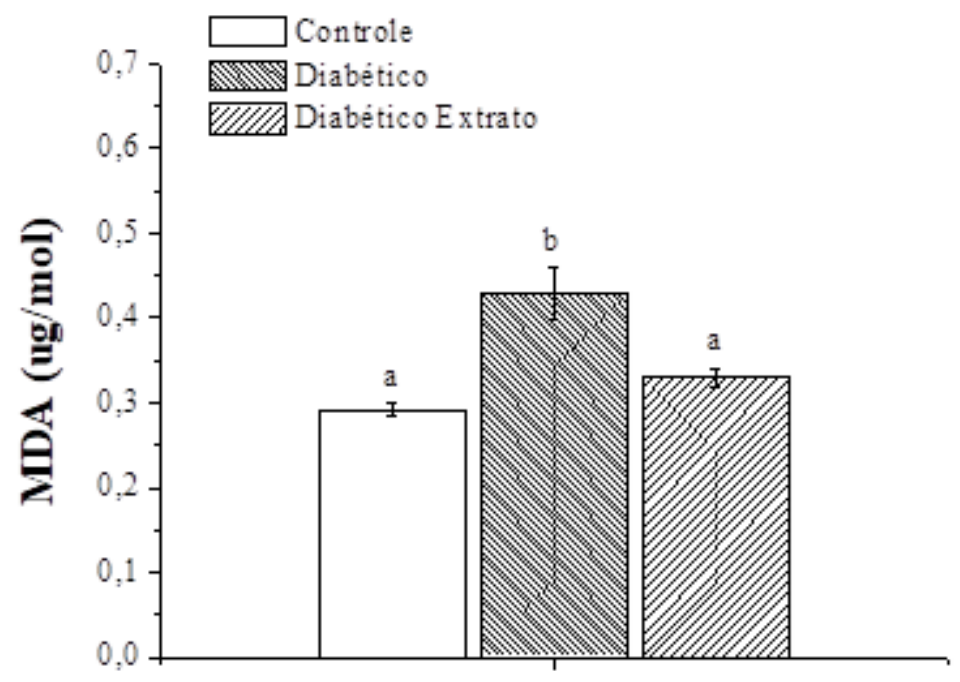

Legenda: Os dados representam os valores de MDA (ug/mol. As letras iguais acima da coluna indicam que as médias foram significativamente iguais $(\mathrm{p}<0,05)$, de acordo com o teste de Tukey a $5 \%$ de significância $(\alpha=0,05)$. Fonte: Autores.

Nos ratos do grupo controle sem diabetes os níveis de lipoperoxidação - MDA foi de 0,29512, nos ratos diabéticos a concentração de malonaldeíno foi consideravelmente superior $(0,42916)$ que dos ratos do grupo sem diabetes. Após o tratamento essa concentração foi reduzida significativamente $(0,33477)$ nos ratos tratados com o extrato de $R$. Sativus., mostrando a diminuição do dano oxidativo.

Estudos avaliaram o estresse oxidativo em outras doenças, como câncer, doença cardiovascular, aterosclerose, doença de alzheimer, doença de parkinson e como no estudo a diabetes mellitus, sendo um importante biomarcador de dano oxidativo nessas doenças humanas (Taniguchi et al., 2006).

A interação entre espécies reativas de oxigênio (EROs) com os lipídeos, causam alterações peroxidativas que resultam em elevação dos produtos da peroxidação lipídica como malonaldeído (MDA). De acordo com estudos, uma avaliação da glândula parótida em ratos diabéticos mostrou que esses comparados com não diabéticos apresentaram valores maiores de MDA, visto que nesse mesmo estudo não foram observados diferença nos valores de MDA da glândula submandibular entre os grupos da pesquisa (Perestrelo, 2018). 
Gráfico 2 - Níveis das proteínas carboniladas.

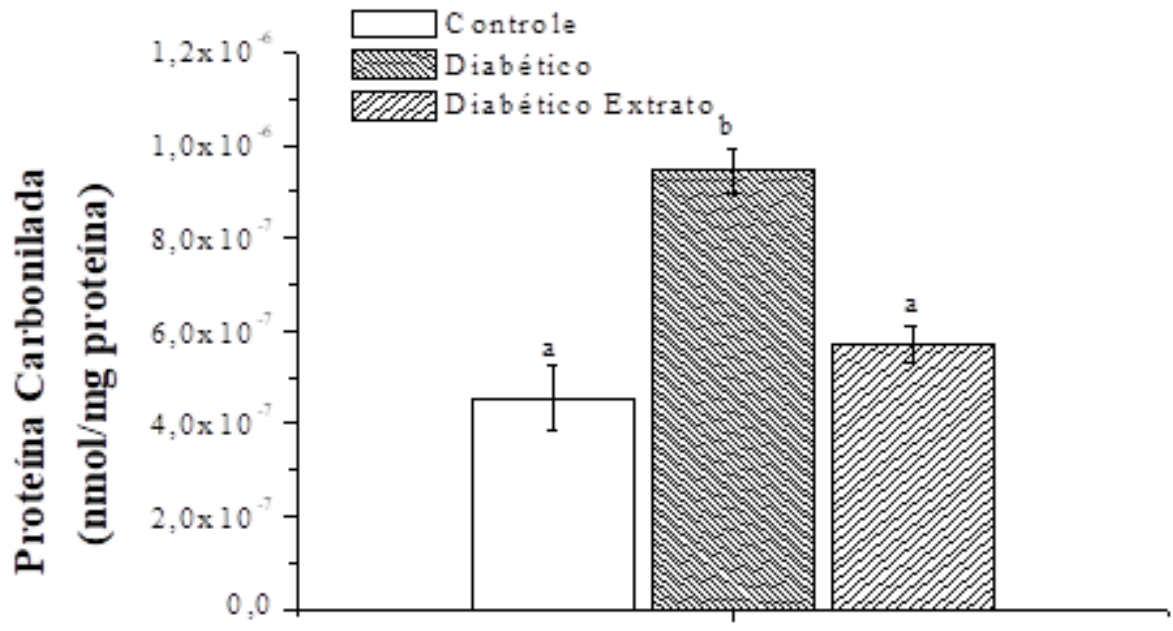

Legenda: Os dados representam os valores de proteína carbonilada (nmol/mg proteína). As letras iguais acima da coluna indicam que as médias foram significativamente iguais $(\mathrm{p}<0,05)$, de acordo com o teste de Tukey a $5 \%$ de significância $(\alpha=0,05)$. Fonte: Autores.

Nos ratos do grupo controle sem diabetes a concentração de proteínas carboniladas foi de 4,55914 x $10^{-7}$, nos ratos diabéticos essa concentração foi de 9,44154 x ${ }^{10-7}$. Após o tratamento com o extrato a concentração de proteínas carboniladas foi reduzida, sendo significativamente satisfatória $\left(5,72284 \times 10^{-7}\right)$ e mostrando diminuição do dano oxidativo nos ratos tratados com R. Sativus.

As principais mudanças da estrutura de proteínas podem ser avaliadas pelas dosagens de proteína carbonilada, perda de grupos tióis e produtos de oxidação proteica avançada (Rocha Navarro et al., 2019). Assim como nesse estudo, outros pesquisadores já avaliaram potenciais antioxidantes em ratos diabéticos utilizando outros extratos. Lage et al., 2018 mostrou que a farinha da polpa de buriti, Mauritia flexuosa, diminuiu o dano oxidativo em ratos diabéticos, e para fazer essa avaliação utilizaram entre outros biomarcardores as proteínas carboniladas, mostrando que o uso desse marcador tem grande potencial em registrar dano oxidativo em ratos com diabetes mellitus. Uma pesquisa realizada por Rocha Navarro et al. 2019 comparou as concentrações de proteínas carboniladas e a capacidade antioxidante total no fluido do sulco gengival de pacientes com diagnóstico recente de diabetes mellitus tipo 2 (DM2) com periodontite, sem periodontite e com gengivite, eles concluíram que as proteínas carboniladas no grupo de pacientes com DM2 e periodontite apresentaram diferença significativa, indicando o dano oxidativo sinérgico de ambas as patologias.

Silva et al., 2011 relatou que o uso da proteína carbonilada como biomarcador possui vantagens em relação a outros marcadores, como sua rápida formação, grande estabilidade e longo tempo de vida. Evidenciando assim que esses compostos carbonilados podem contribuir para as complicações diabéticas.

Desde 1987, estudos já relatavam doenças bucais em pacientes com DM, Bartholomew et al., 1987 foi um dos primeiros que fez uma análise da ocorrência de candidíase em pacientes com DM. Mauri-Obradors et al., 2017 organizou através de uma revisão sistemática estudos que mostravam os registros de manifestações bucais relacionados com a DM, e concluíram com a pesquisa que a periodontite é a manifestação bucal mais prevalente, em seguida a candidíase e em terceiro lugar a hipossalivação em pacientes com diabetes. A hipossalivação, entre outros fatores, se deve ao ataque dos radicais livres às biomoléculas que causam o mau funcionamento da glândula salivar.

Estudos mostram que a hiperglicemia pode aumentar os marcadores de inflamação crônica e contribuir para o aumento da geração de espécies reativas de oxigênio, e esse desequilíbrio entre radicais livres e antioxidantes pode levar a disfunção 
vascular. Logo, novas alternativas terapêuticas devem ser estudadas e pesquisadas almejando a diminuição do estresse oxidativo e consequentemente diminuir as complicações da DM.

\section{Conclusão}

O extrato hidroetanólico das folhas de Raphanus sativus apresentou resultados positivos, apresentando efeitos antioxidativos que foram capazes de reverter os danos causados pelo estresse oxidativo, quando analisados a lipoperoxidação (MDA) e oxidação proteica (proteínas carboniladas) nas glândulas submandibulares dos ratos diabéticos. O trabalho mostrou que o extrato hidroetanólico de Raphanus sativus pode ser uma opção terapêutica para o controle dos danos do DM que envolvam a cavidade bucal. Salienta-se a necessidade de ser estudado mais detalhadamente em outros modelos experimentais, visando elucidar os efeitos adicionais que possam vir a colaborar com nossos achados.

\section{Referências}

American Diabetes Association. (2004). Nephropathy in diabetes. Diabetes care, 27(suppl 1), s79-s83.

Banihani, S. A. (2017). Radish (Raphanus sativus) and diabetes. Nutrients, 9(9), 1014.

Barbosa, K. B. F., Costa, N. M. B., Alfenas, R. D. C. G., De Paula, S. O., Minim, V. P. R., \& Bressan, J. (2010). Estresse oxidativo: conceito, implicações e fatores modulatórios. Revista de nutrição, 23(4), 629-643.

Bartholomew, G. A., Rodu, B., \& Bell, D. S. (1987). Oral candidiasis in patients with diabetes mellitus: a thorough analysis. Diabetes Care, 10(5), 607-612.

Bergamaschi KB. Capacidade antioxidante e composição química de resíduos vegetais visando seu aproveitamento (Doctoral dissertation, Universidade de São Paulo).

Borba, A. M., \& Macedo, M. (2006). Plantas medicinais usadas para a saúde bucal pela comunidade do bairro Santa Cruz, Chapada dos Guimarães, MT, Brasil. Acta Botanica Brasilica, 20(4), 771-782.

Bradford, M. M. (1976). A rapid and sensitive method for the quantitation of microgram quantities of protein utilizing the principle of protein-dye binding. Analytical biochemistry, 72(1-2), 248-254.

Escott-Stump, S. Y. L. V. I. A., \& ao Diagnóstico, N. R. (2007). Tratamento. $5^{\text {a }}$ edição.

Feijó, A. M., Bueno, M. E. N., Ceolin, T., Linck, C. L., Schwartz, E., Lange, C., \& Heiden, G. (2012). Plantas medicinais utilizadas por idosos com diagnóstico de Diabetes mellitus no tratamento dos sintomas da doença. Revista Brasileira de Plantas Medicinais, 14(1), 50-56.

França, B. K., Alves, M. R. M., Souto, F. M. S., Tiziane, L., Boaventura, R. F., Guimarães, A., \& Alves Jr, A. (2013). Peroxidação lipídica e obesidade: Métodos para aferição do estresse oxidativo em obesos. GE jornal português de gastrenterologia, 20(5), 199-206.

Gancheva, M. S., Dodueva, I. E., Lebedeva, M. A., Tvorogova, V. E., Tkachenko, A. A., \& Lutova, L. A. (2016). Identification, expression, and functional analysis of CLE genes in radish (Raphanus sativus L.) storage root. BMC plant biology, 16(1), 23-33.

Grochanke, B. S., Gehrke, I. T. S., Goettems-Fiorin, P. B., Bruxel, M. A., Basso, E. G. P., Heck, T. G., \& Ludwig, M. S. (2016). Compostos fenólicos da casca de Handroanthus heptaphyllus (Mart.) Mattos e efeitos do extrato aquoso no perfil lipídico, glicêmico e na lipoperoxidação em ratos diabéticos. Revista Brasileira de Plantas Medicinais, 18(1), 264-272.

Grotto, D., Valentini, J., Boeira, S., Paniz, C., Maria, L. S., Vicentini, J., \& Cardoso, S. G. (2008). Evaluation of the stability of the oxidative stress plasmatic biomarker: malondialdehyde. Química Nova, 31(2), 275-279.

Jaouhari, J. T., Lazrek, H. B., \& Jana, M. (2000). The hypoglycemic activity of Zygophyllum gaetulum extracts in alloxan-induced hyperglycemic rats. Journal of ethnopharmacology, 69(1), 17-20.

Jones, B., Roberts, P. J., Faubion, W. A., Kominami, E., \& Gores, G. J. (1998). Cystatin A expression reduces bile salt-induced apoptosis in a rat hepatoma cell line. American Journal of Physiology-Gastrointestinal and Liver Physiology, 275(4), G723-G730.

Lage, N. N., Lopes, J. M. M., Pereira, R. R., Guerra, J. F. C., Pereira, M. D. F. A., Silva, M., ... \& Pedrosa, M. L. (2018). Antioxidant potential of Buriti (Mauritia flexuosa) pulp flour in diabetic rats. Archivos Lafinoamericanos de Nutrición, 68, 59.

Mauri-Obradors, E., Estrugo-Devesa, A., Jané-Salas, E., Viñas, M., \& López-López, J. (2017). Oral manifestations of Diabetes Mellitus. A systematic review. Medicina oral, patologia oral y cirugia bucal, 22(5), e586.

Negri, G. (2005). Diabetes melito: plantas e princípios ativos naturais hipoglicemiantes. Revista Brasileira de Ciências Farmacêuticas, 41(2), 121-142.

Pereira A.S. et al. (2018). Metodologia da pesquisa científica. Ed. UAB/NTE/UFSM. 
Research, Society and Development, v. 10, n. 2, e21610212447, 2021

(CC BY 4.0) | ISSN 2525-3409 | DOI: http://dx.doi.org/10.33448/rsd-v10i2.12447

Perestrelo, B. D. O. (2018). Potencial antioxidante do chá de camomila nas glândulas salivares e sua influência no estado glicêmico de ratos diabéticos (Doctoral dissertation, Universidade de São Paulo).

Prista, L. V. N., Alves, A. C., Lobo, J. S., \& Morgado, R. (2014). Tecnologia farmacêutica. Fundação Calouste Gulbenkian. Serviço de Educação e Bolsas.

Rocha Navarro, M. L., Fajardo Araujo, M. E., Orrantia Bustos, M. A., Ramírez Emiliano, J., \& Salinas Pedroza, G. E. (2019). Niveles de proteína carbonilada y capacidad antioxidante total en pacientes con diabetes mellitus tipo 2 de reciente diagnóstico y enfermedad periodontal. Rev. ADM, 203-208.

Santos, A. P. A. D., \& Rieder, A. (2017). Análise de objetivos e conclusões de estudos com nove plantas usadas para o controle de diabetes em Mato Grosso.

Silva, A. B., Lopes, G. D. S., Neves, T. V. B., Barros, G. B. S., Reis, L.F.C., Salles, B. C. C., Cerdeira, C.D., Moraes, G.O.I. (2019). Extrato etanólico das folhas de Raphanus sativus L. var. oleífera Metzg (nabo forrageiro): efeitos antihiperglicêmico, antidislipidêmico e antioxidante em ratos com Diabetes Mellitus tipo 1. Revista Fitos. Rio de Janeiro, 13(1), 38-48.

Silva, M., Lima, W. G. D., Silva, M. E., \& Pedrosa, M. L. (2011). Effect of streptozotocin on the glycemic and lipid profiles and oxidative stress in hamsters. Arquivos Brasileiros de Endocrinologia \& Metabologia, 55(1), 46-53.

Taniguchi, H., Kobayashi-Hattori, K., Tenmyo, C., Kamei, T., Uda, Y., Sugita-Konishi, Y., \& Takita, T. (2006). Effect of Japanese radish (Raphanus sativus) sprout (Kaiware-daikon) on carbohydrate and lipid metabolisms in normal and streptozotocin-induced diabetic rats. Phytotherapy Research: An International Journal Devoted to Pharmacological and Toxicological Evaluation of Natural Product Derivatives, 20(4), 274-278.

Vasconcelos, S. M. L., Goulart, M. O. F., Moura, J. B. D. F., Manfredini, V., Benfato, M. D. S., \& Kubota, L. T. (2007). Espécies reativas de oxigênio e de nitrogênio, antioxidantes e marcadores de dano oxidativo em sangue humano: principais métodos analíticos para sua determinação. Química nova, 30(5), 13231338 .

Xu, T., Weng, Z., Pei, C., Yu, S., Chen, Y., Guo, W., \& Sun, J. (2017). The relationship between neutrophil-to-lymphocyte ratio and diabetic peripheral neuropathy in Type 2 diabetes mellitus. Medicine, 96(45). 